\title{
Flow intermittence alters carbon processing in rivers through chemical diversification of leaf litter
}

\author{
Rubén del Campo ${ }^{1}$, Roland Corti ${ }^{2}$, and Gabriel Singer ${ }^{3}$ \\ ${ }^{1}$ Leibniz Institute of Freshwater Ecology and Inland Fisheries \\ ${ }^{2}$ Irstea Centre de Lyon-Villeurbanne \\ ${ }^{3}$ University of Innsbruck
}

October 14, 2020

\begin{abstract}
The dry phase of intermittent rivers promotes the emergence of diverse terrestrial and aquatic habitats where large amounts of leaf litter can accumulate. This environmental heterogeneity can cause diverse chemical alterations in leaf litter by the cooccurrence of multiple physical and biological degradation processes across these different habitats. After flow resumption, these chemically diversified leaves are mixed and continue decomposition downstream in fully aquatic conditions. We hypothesized that environmental heterogeneity during the dry phase can translate into a chemical diversification of leaf litter, that may affect leaf litter decomposition in re-established lotic conditions. Our laboratory treatments mimicking dry-phase habitats caused a strong chemical diversification of leaf litter, which - upon combination in mixed litter bags - accelerated its decomposition in a perennial river reach. Intermittent river reaches may act as hotspots of organic matter diversification, with potential implications on $\mathrm{C}$ processing at river-network scale.
\end{abstract}

\section{Hosted file}

Appendix S1.docx available at https://authorea.com/users/348452/articles/473751-flowintermittence-alters-carbon-processing-in-rivers-through-chemical-diversification-of-

leaf-litter

\section{Hosted file}

del_Campo_et_al_2020_L\&0_letters.pdf available at https://authorea.com/users/348452/ articles/473751-flow-intermittence-alters-carbon-processing-in-rivers-through-chemicaldiversification-of-leaf-litter 


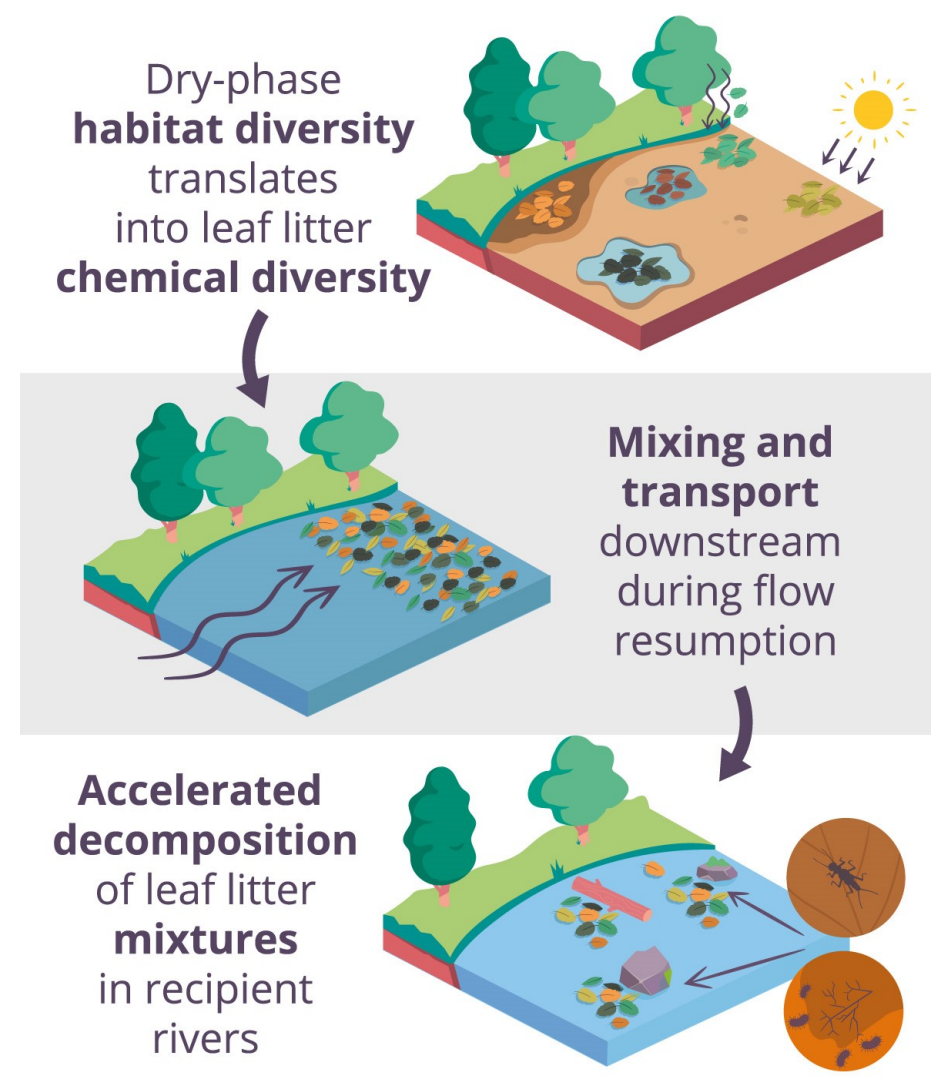

Figure 1: Graphical Abstract 